\title{
TINGKAT PENGETAHUAN KESEHATAN GIGI DAN MULUT DENGAN PENYULUHAN MENGGUNAKAN MEDIA FLIP CHART DAN BONEKA ANIMASI PADA ANAK KELAS V SD NEGERI 105307 SUKARAYA PANCUR BATU TAHUN 2014
}

\author{
Asnita Bungaria Simaremare, Rosdiana T Simaremare \\ Jurusan Keperawatan Gigi Politeknik Kesehatan Kemenkes Medan
}

\begin{abstract}
Abstrak
Penyuluhan merupakan suatu penerangan yang menekankan pada objek tertentu dan hasil yang diharapkan adalah perubahan perilaku individu atau sekelompok orang. Penyuluhan merupakan suatu usaha menyebarluaskan hal-hal yang baru agar masyarakat tertarik melaksanakannya dalam kehidupan mereka. Penelitian ini bertujuan untuk mengetahui perbandingan tingkat pengetahuan anak kelas V SD Negeri 064026 tentang kesehatan gigi dan mulut dengan penyuluhan menggunakan media flip chart dan boneka animasi. Jenis penelitiannya adalah deskriptif dengan metode suvei, dengan populasi anak kelas V yang berjumlah 40 orang. Dari hasil penelitian diperoleh tingkat pengetahuan anak sebelum penyuluhan dengan media flip chart yang mendapat kriteria baik 5 responden, kriteria sedang 10 responden dan kriteria buruk 5 responden. Sebelum penyuluhan dengan media boneka animasi yang mendapat kriteria baik 6 responden, kriteria sedang 5 responden dan kriteria buruk 9 responden. Sesudah penyuluhan dengan media flip chart yang mendapat kriteria baik 11 responden, kriteria sedang 9 responden dan kriteria buruk tidak ada. Sesudah penyuluhan dengan media boneka animasi yang mendapat kriteria baik 19 responden, kriteria sedang 1 responden dan kriteria buruk tidak ada. Kesimpulan penelitian menunjukkan bahwa penyuluhan dengan menggunakan media boneka animasi lebih meningkatkan pengetahuan anak kelas V SD Negeri 064026. Hal ini dikarenakan boneka animasi lebih menarik perhatian anak-anak, sehingga pesan dalam penyuluhan lebih dapat dipahami.
\end{abstract}

Kata Kunci : Pengetahuan, Flip Chart, Boneka Animasi

\section{LATAR BELAKANG}

Masalah utama kesehatan gigi di Indonesia adalah kurangnya menjaga kebersihan gigi dan mulut. Berdasarkan Survei Kesehatan Rumah Tangga (SKRT, 2004), prevalensi karies di Indonesia mencapai $90.05 \%$ dan ini tergolong lebih tinggi dibandingkan dengan negara berkembang lainnya. Masalah tersebut menjadi perhatian yang sangat penting dalam pembangunan kesehatan yang salah satunya disebabkan oleh rentannya anak usia sekolah dari gangguan kesehatan gigi. Usia sekolah merupakan masa untuk meletakkan landasan kokoh bagi terwujudnya manusia yang berkualitas dan kesehatan merupakan faktor penting yang menentukan kualitas sumber daya manusia. Karies gigi dan penyakit periodontal adalah penyakit gigi dan mulut yang banyak diderita masyarakat Indonesia (Andhika, 2012).

Di Indonesia sebanyak 89\% anak dibawah usia 12 tahun menderita penyakit gigi dan mulut. Kondisi itu akan sangat berpengaruh pada derajat kesehatan, proses tumbuh kembang bahkan masa depan anak. Rasa sakit pada gigi dan mulut jelas menurunkan selera makan mereka. Dampak lainnya, kemampuan belajar mereka akan turun sehingga akan berpengaruh pada prestasi belajar hingga hilangnya masa depan anak. Salah satu upaya untuk mencegah terjadinya penyakit gigi dan mulut adalah perlu diadakan penyuluhan kesehatan gigi secara dini pada anak, karena penyuluhan kesehatan gigi merupakan tindakan pencegahan primer sebelum terjadinya suatu penyakit. Penyuluhan kesehatan gigi memegang peranan penting di sekolah terutama untuk meningkatkan kesadaran para anak dalam menjaga giginya agar bertahan lama (Andhika, 2012).

Penyuluhan adalah suatu penerangan yang menekankan pada suatu objek tertentu dan hasil yang diharapkan adalah suatu perubahan perilaku individu atau sekelompok orang. Penyuluhan merupakan suatu usaha menyebarluaskan hal-hal yang baru agar masyarakat tertarik dan berminat untuk melaksanakannya dalam kehidupan mereka sehari-hari. Penyuluhan juga merupakan suatu kegiatan mendidik sesuatu kepada masyarakat, memberi pengetahuan, informasi-informasi, dan kemampuan-kemampuan agar dapat membentuk sikap dan berperilaku hidup menurut apa yang seharusnya. Hakekatnya penyuluhan merupakan suatu kegiatan dalam rangka mengubah masyarakat menuju keadaan yang lebih baik (Gondoyoewono, 2004).

Media merupakan perantara atau pengantar yang digunakan oleh pendidik dalam menyampaikan bahan 
pendidikan atau pengajaran. Media juga dapat menimbulkan minat atau rangsangan dalam belajar. Dimana semakin banyak panca indera yang digunakan untuk menerima sesuatu maka semakin jelas pula pengertian atau pengetahuan yang diperoleh (Suiraoka, 2012).

Keberadaan media dalam pendidikan kesehatan gigi sangat diperlukan oleh para tenaga kesehatan. Karena dengan media, pesan-pesan kesehatan dapat disampaikan secara lebih jelas, sehingga sasaran akan menerima pesan tersebut dengan jelas dan tepat. Disamping itu melalui media, sasaran mampu memahami suatu fakta yang dianggap rumit (Suiraoka, 2012).

Berdasarkan uraian diatas penulis akan melakukan penelitian mengenai tingkat pengetahuan kesehatan gigi dan mulut dengan metode penyuluhan menggunakan media flip chart dan boneka animasi pada anak kelas V SD Negeri 105307 Sukaraya Pancur Batu Tahun 2014

\section{RUMUSAN MASALAH}

Berdasarkan latar belakang diatas, terlihat bahwa pengetahuan anak-anak tentang kesehatan gigi dan mulut masih rendah. Untuk itu peneliti ingin tahu bagaimanakah perbandingan tingkat pengetahuan kesehatan gigi dan mulut pada penyuluhan dengan menggunakan media flip chart dan boneka animasi.

\section{TUJUAN PENELITIAN}

\section{Tujuan Umum}

Penelitian ini bertujuan untuk mengetahui gambaran perbandingan tingkat pengetahuan kesehatan gigi dan mulut dengan penyuluhan menggunakan media flip chart dan boneka animasi.

\section{Tujuan Khusus}

1. Untuk mengetahui tingkat pengetahuan anak kelas $\mathrm{V}$ dalam memelihara kesehatan gigi dan mulut sebelum diberi penyuluhan.

2. Untuk mengetahui tingkat pengetahuan anak kelas $\mathrm{V}$ tentang kesehatan gigi dan mulut setelah diberi penyuluhan dengan menggunakan media flip chart.

3. Untuk mengetahui tingkat pengetahuan anak kelas $\mathrm{V}$ tentang kesehatan gigi dan mulut setelah diberi penyuluhan dengan menggunakan media boneka animasi.

\section{Manfaat Penelitian}

1. Sebagai informasi atau masukan bagi pihak sekolah tentang perbandingan pengetahuan pada penyuluhan menggunakan media flip chart dan boneka animasi pada anak kelas $\mathrm{V}$ dalam memelihara kesehatan gigi dan mulut pada anak kelas V SD Negeri 105307 Sukaraya Pancur Batu Tahun 2014.

2. Menambah pengetahuan anak kelas V SD Negeri 105307 Sukaraya Pancur Batu Tahun 2014 dalam memelihara kesehatan gigi dan mulut.
3. Hasil penelitian diharapkan sebagai masukan bagi peneliti lain dan sebagai bahan referensi di perpustakaan Jurusan Keperawatan Gigi Politeknik Kesehatan Kemenkes Medan.

\section{METODE PENELITIAN}

\section{Jenis dan Desain Penelitian}

Jenis penelitian yang dilakukan adalah penelitian deskriptif dengan metode survei yang bertujuan untuk mengetahui perbandingan tingkat pengetahuan anak dengan penyuluhan menggunakan media flip chart dan boneka animasi.

\section{Lokasi dan waktu penelitian}

Lokasi penelitian merupakan daerah atau tempat penelitian dilakukan. Penelitian dilakukan pada anak kelas V di SD Negeri 105307 Sukaraya Pancur Batu Tahun 2014.

\section{Waktu Penelitian}

Penelitian ini dilakukan dari bulan September sampai dengan bulan November 2014.

\section{Populasi dan Sampel Penelitian}

Populasi adalah wilayah generelasisasi yang terdiri atas objek/subjek yang mempunyai kuantitas dan karakteristik tertentu yang ditetapkan oleh peneliti untuk dipelajari dan kemudian ditarik kesimpulannya (Hidayat, 2008).

Populasi dalam penelitian ini adalah anak kelas V SD Negeri 105307 Sukaraya Pancur Batu Tahun 2014.

\section{Sampel Penelitian}

Sampel adalah objek penelitian yang dianggap mewakili keseluruhan populasi. Dalam pengambilan sampel pada penelitian ini mengarah pada pendapat Suharsimi Arikunto (2006) yang mengatakan "bahwa apabila subjek penelitian kurang dari 100 dapat diambil semua, sehingga sampel dalam penelitian ini adalah berjumlah 40 orang.

\section{Jenis dan Cara Pengumpulan Data}

Dalam penelitian ini data yang digunakan adalah data sekunder. Data sekunder adalah data yang diperoleh dari lokasi penelitian, yaitu tentang identitas pasien yang mencakup nama, umur, jenis kelamin, dan alamat. Datadata ini dapat diperoleh dengan memberikan kuesioner.

Hal pertama yang dilakukan peneliti adalah peneliti membagi anak kelas $\mathrm{V}$ menjadi dua kelompok. Kelompok pertama diberikan penyuluhan dengan media flip chart dan kelompok kedua diberikan penyuluhan dengan media boneka animasi.

A. Persiapan

Pengumpulan data dilakukan dengan pemeriksaan secara langsung (observasi) dan juga melalui kuesioner. Data langsung diambil oleh peneliti ke lokasi penelitian yaitu pada anak kelas V SD Negeri 105307 Sukaraya Pancur Batu Tahun 2014. 
Pada hari pertama sebelum melakukan penyuluhan, peneliti membuat satu tim yang terdiri dari dua orang dan juga mempersiapkan alat dan bahan yang akan digunakan, yaitu:

a. Orang pertama bertugas membagikan kuesioner

b. Orang kedua sebagai pembantu yang bertugas untuk memeriksa serta mencatat hasil kuesioner.

c. Alat dan Bahan
a. Alat terdiri dari:
1. Flip chart
2. Boneka animasi
3. Model
4. Alat tulis
b. Bahan terdiri dari:
1. Kuesioner
2. Sikat Gigi

B. Pelaksanaan

Kegiatan yang dilakukan adalah :

1. Kelompok pertama yang akan diberikan penyuluhan tetap berada didalam kelas, sedangkan kelompok kedua disuruh menunggu diluar kelas.

2. Sebelum memberikan kuesioner terlebih dahulu peneliti menjelaskan maksud dan tujuan datang, kemudian kuesioner dibagikan pada setiap anak untuk di jawab langsung.

3. Setelah kuesioner dijawab oleh anak-anak, kuesioner dikumpulkan dan diperiksa.

4. Kemudian kuesioner yang sudah dikumpulkan dinilai.

5. Kemudian setelah didapatkan hasil pemeriksaan oleh orang yang pertama, maka orang kedua mencatat hasil yang telah di peroleh.

6. Setelah itu, hari berikutnya kelompok kedua diberikan kuesioner terlebih dahulu.

7. Setelah selesai dijawab, peneliti memeriksa kembali dan menilai hasil jawaban anak.

8. Kemudian diberikan penyuluhan dengan menggunakan media boneka animasi sebagai alat bantu dalam penyuluhan.

9. Kuesioner dibagikan kembali pada anak.

10. Setelah semua anak selesai menjawab, kuesioner dikumpul kembali dan diperiksa.

11. Setelah selesai diperiksa kemudian peneliti menjelaskan kembali jawaban yang benar.

12. Kemudian data-data tersebut dimasukkan kedalam tabel distribusi frekuensi.

\section{Pengolahan dan Analisa Data}

Setelah pengumpulan data maka dilakukan analisa data dengan teknik sebagai berikut :

1. Editing (Pemeriksaan)

Editing adalah upaya untuk memeriksa kembali kebenaran data yang telah diperoleh.

Dalam melakukan editing ada beberapa hal yang harus diperhatikan :

a. Memeriksa kelengkapan data b. Memeriksa kesinambungan data

c. Memeriksa keseragaman data

2. Coding

Coding adalah pemberian kode numeric (angtka) terhadap data yang terdiri atas beberapa kategori.

3. Tabulasi data

Tabulasi data dilakukan jika semua masalah dan coding telah selesai, sehingga data selanjutnya dimasukkan kedalam tabel.

\section{HASIL DAN PEMBAHASAN}

\section{Hasil Penelitian}

Berdasarkan hasil penelitian yang dilakukan pada 40 anak kelas V SD Negeri 105307 Sukaraya Pancur Batu Tahun 2014, maka didapat hasil sebagai berikut :

Tabel 1. Distribusi Frekuensi Responden Berdasarkan Tingkat Pengetahuan Anak Kelas V SD Negeri 105307 Sebelum Diberi Penyuluhan Dengan Media Flip Chart

\begin{tabular}{cccc}
\hline No & Tingkat Pengetahuan & $\mathrm{N}$ & $\%$ \\
\hline 1. & Baik & 5 & $25 \%$ \\
2. & Sedang & 10 & $50 \%$ \\
3. & Buruk & 5 & $25 \%$ \\
\hline & Total & 20 & $100 \%$ \\
\hline
\end{tabular}

Dari tabel di atas terlihat bahwa pengetahuan anak kelas V SD Negeri 105307 sebelum diberi penyuluhan tentang Kesehatan Gigi dan Mulut, yang mendapat kriteria baik sebanyak 5 responden $(25 \%)$, kriteria sedang sebanyak 10 responden $(50 \%)$ dan kriteria buruk sebanyak 5 responden (25\%).

Tabel 2. Distribusi Frekuensi Responden Berdasarkan Tingkat Pengetahuan Anak Kelas V SD Negeri 105307 Sebelum Diberi Penyuluhan Dengan Media Boneka Animasi

\begin{tabular}{cccc}
\hline No & Tingkat Pengetahuan & $\mathrm{N}$ & $\%$ \\
\hline 1. & Baik & 6 & $30 \%$ \\
2. & Sedang & 5 & $25 \%$ \\
3. & Buruk & 9 & $45 \%$ \\
\hline & Total & 20 & $100 \%$ \\
\hline
\end{tabular}

Dari tabel di atas terlihat bahwa pengetahuan anak kelas V SD Negeri 105307 sebelum diberi penyuluhan tentang Kesehatan Gigi dan Mulut, yang mendapat kriteria baik sebanyak 6 responden (30\%), kriteria sedang sebanyak 5 responden $(5 \%)$ dan kriteria buruk sebanyak 9 responden $(45 \%)$.

Tabel 3. Distribusi Frekuensi Berdasarkan Tingkat Pengetahuan Pada 20 Anak Kelas V SD Negeri 105307 Setelah Diberi Penyuluhan Dengan Media Flip Chart

\begin{tabular}{cccc}
\hline No & Tingkat Pengetahuan & $\mathrm{N}$ & $\%$ \\
\hline 1. & Baik & 11 & $55 \%$ \\
2. & Sedang & 9 & $45 \%$ \\
3. & Buruk & 0 & $0 \%$ \\
\hline \multicolumn{4}{r}{} \\
\hline
\end{tabular}


Dari tabel di atas dilihat bahwa pengetahuan 20 anak kelas V SD Negeri 105307 setelah diberi penyuluhan tentang Kesehatan Gigi dan Mulut dengan menggunakan Media Flip Chart, yang mendapat kriteria baik sebanyak 11 responden $(55 \%)$, kriteria sedang sebanyak 9 responden (45\%) dan kriteria buruk tidak ada (0\%).

\begin{tabular}{llcc} 
Tabel 4. & Distribusi & \multicolumn{1}{c}{ Frekuensi } & $\begin{array}{r}\text { Responden } \\
\text { Berdasarkan Tingkat Pengetahuan Pada 20 }\end{array}$ \\
& $\begin{array}{l}\text { Anak Kelas V SD Negeri 105307 } \\
\text { Diberi Penyuluhan Dengan Media }\end{array}$ & $\begin{array}{c}\text { Setelah } \\
\text { Boneka }\end{array}$ \\
& $\begin{array}{l}\text { Animasi } \\
\text { Animan }\end{array}$ & N & $\%$ \\
\hline No & Tingkat Pengetahuan & 19 & $95 \%$ \\
\hline 1. & Baik & 1 & $5 \%$ \\
2. & Sedang & 0 & $0 \%$ \\
3. & Buruk & 20 & $100 \%$ \\
\hline & Total & &
\end{tabular}

Dari tabel di atas dilihat bahwa pengetahuan anak kelas V SD Negeri 105307 setelah diberi penyuluhan tentang Kesehatan Gigi dan Mulut dengan menggunakan media boneka animasi, yang mendapat kriteria baik sebanyak 19 responden (95\%), kriteria sedang sebanyak 1 responden $(5 \%)$ dan kriteria buruk tidak ada $(0 \%)$.

\section{PEMBAHASAN}

Dari tabel 1 distribusi frekuensi responden berdasarkan tingkat pengetahuan anak kelas V SD Negeri 105307 sebelum diberi penyuluhan dengan media flip chart tentang Kesehatan Gigi dan Mulut yaitu yang pengetahuannya baik sebanyak 5 orang (25\%), yang sedang sebanyak 10 orang $(50 \%)$, dan pengetahuan yang buruk sebanyak 5 orang (25\%). Hal ini dikarenakan kurangnya perhatian terhadap kesehatan gigi dan mulut. Selain itu belum pernah diadakan penyuluhan kesehatan gigi dan mulut kepada semua anak.

Dari tabel 2 distribusi frekuensi responden berdasarkan tingkat pengetahuan anak kelas V SD Negeri 105307 sebelum diberi penyuluhan dengan media boneka animasi tentang Kesehatan Gigi dan Mulut yaitu yang pengetahuannya baik sebanyak 6 orang (30\%), yang sedang sebanyak 5 orang (25\%), dan pengetahuan yang buruk sebanyak 9 orang (45\%). Hal ini juga dikarenakan kurangnya perhatian terhadap kesehatan gigi dan mulut. Selain itu belum pernah diadakan penyuluhan kesehatan gigi dan mulut kepada semua anak.

Dari tabel 3 distribusi frekuensi responden berdasarkan tingkat pengetahuan pada 20 anak kelas V SD Negeri 105307 setelah diberi penyuluhan dengan media flip chart yang mendapat kriteria baik sebanyak 11 orang $(55 \%)$, kriteria yang sedang 9 orang $(45 \%)$, dan kriteria yang buruk tidak ada $(0 \%)$. Pengetahuan anak meningkat setelah diberi penyuluhan dengan media flip chart, melalui media ini anak tidak hanya dapat mendengarkan penyuluhan tetapi juga dapat melihat gambar sesuai dengan materi penyuluhan. Tetapi karena flip chart hanya diletakkan dibagian depan kelas dan terlalu kecil untuk sasaran 20 orang maka sebagian anak tidak dapat melihat semua isi dari flip chart, terutama untuk anak yang duduk pada posisi bagian belakang.
Dari tabel 4 distribusi frekuensi responden berdasarkan tingkat pengetahuan pada 20 anak kelas V SD Negeri 105307 setelah diberi penyuluhan dengan Media Boneka Animasi, yang mendapat kriteria baik sebanyak 19 orang $(95 \%)$, kriteria yang sedang 1 orang $(5 \%)$, dan untuk kriteria yang buruk tidak ada $(0 \%)$. Pengetahuan anak semakin meningkat setelah diberi penyuluhan dengan menggunakan media boneka animasi. Hal ini dikarenakan media ini lebih mendapat perhatian khusus pada sasaran anak-anak. Anak-anak dapat belajar sambil bermain sehingga materi penyuluhan dapat lebih dicerna. Selain itu media ini mudah dibawa-bawa sehingga semua anak kelas $\mathrm{V}$ dapat melihat media tersebut termasuk yang duduk pada posisi bagian belakang.

Dari hasil penelitian diperoleh dapat dilihat bahwa sebelum diberi penyuluhan pengetahuan anak kelas V SD Negeri 105307 tentang kesehatan gigi dan mulut masih rendah. Terutama untuk pertanyaan nomor 2 yaitu tentang penyebab gigi berlubang semua anak menjawab salah $(100 \%)$. Hal ini terjadi karena pendidikan tentang kesehatan gigi dan mulut pada anak kelas V SD Negeri 105307 masih kurang. Selain itu pada pertanyaan nomor 4 tentang lamanya waktu menyikat gigi juga rata-rata menjawab salah. Sebagian besar anak tahu waktu yang tepat untuk menyikat gigi tetapi masih belum tahu lamanya menyikat gigi yang baik dan benar.

Hasil penelitian menunjukkan bahwa setelah diberi penyuluhan pada 20 anak dengan menggunakan media flip chart, pengetahuan anak semakin meningkat dan tidak ada yang mendapat kriteria buruk. Tetapi masih ada anak yang menjawab salah beberapa pertanyaan, sedangkan pada saat penyuluhan dengan media flip chart tergambar dengan jelas dan juga dilengkapi dengan keterangannya. Selain itu posisi duduk pada bagian belakang juga mempengaruhi kesalahan saat menjawab kuesioner. Hal ini dikarenakan kelemahan media flip chart hanya diletakkan didepan kelas dan tidak mudah untuk dipindah-pindahkan karena mudah robek. Selain itu juga kurang menarik bagi anakanak, sehingga merasa bosan pada penyuluhannya (Suiraoka, 2012).

Sedangkan dari hasil yang diperoleh setelah diberi penyuluhan pada 20 anak dengan menggunakan media boneka animasi, dapat dilihat bahwa pengetahuan anak sudah baik. Hal ini disebabkan media boneka animasi ini sangat disukai, karena bentuknya yang menarik, sehingga anak lebih semangat mendengarkan penyuluhan yang diberikan dan memahami pesan-pesan yang disampaikan dalam penyuluhan.

Dari hasil penelitian terlihat bahwa media boneka animasi lebih dapat meningkatkan pengetahuan anak kelas V SD Negeri 105307 tentang kesehatan gigi dan mulut. Anak-anak pada usia sekolah dasar lebih dapat memahami jika diberikan penyuluhan dengan cara bermain. Tetapi pada masa usia sekolah dasar, anak juga mengalami masa perubahan fisik yang cepat, masa meraih identitas yang tidak bergantung pada orang lain, masa untuk mengalami kelakuan dan berfikir realitik, sehingga anak pada usia sekolah dasar ini dapat juga memahami dan menerima pesan yang ingin disampaikan dalam penyuluhan. 


\section{SIMPULAN DAN SARAN}

\section{Simpulan}

Berdasarkan penelitian serta pembahasan yang telah dilakukan pada anak kelas V SD Negeri 105307 mengenai tingkat pengetahuan kesehatan gigi dan mulut dengan Penyuluhan menggunakan media flip chart dan boneka animasi diperoleh kesimpulan, yaitu :

1. Tingkat pengetahuan pada 20 anak kelas V SD Negeri 105307 sebelum diberi penyuluhan dengan media flip chart tentang kesehatan gigi dan mulut, terdapat kategori baik sebanyak 5 responden $(25 \%)$ yang sedang sebanyak 10 responden $(50 \%)$ dan buruk sebanyak 5 responden $(25 \%)$.

2. Tingkat pengetahuan pada 20 anak kelas V SD Negeri 105307 sebelum diberi penyuluhan tentang kesehatan gigi dan mulut dengan boneka animasi, yang kriteria baik sebanyak 6 responden $(30 \%)$ yang sedang sebanyak 5 responden $(25 \%)$ dan buruk sebanyak 9 responden $(45 \%)$.

3. Tingkat pengetahuan pada 20 anak kelas V SD Negeri 105307 setelah diberi penyuluhan tentang kesehatan gigi dan mulut dengan media flip chart, yang kriteria baik sebanyak 11 responden $(55 \%)$ yang sedang sebanyak 9 responden $(45 \%)$ dan buruk sebanyak 0 responden $(0 \%)$.

4. Tingkat pengetahuan pada 20 anak kelas V SD Negeri 105307 setelah diberi penyuluhan tentang kesehatan gigi dan mulut dengan media boneka animasi, yang mendapat kriteria baik sebanyak 19 responden (95\%) yang sedang sebanyak 1 responden $(5 \%)$ dan buruk sebanyak 0 responden $(0 \%)$.

5. Ada perbandingan tingkat pengetahuan anak kelas V SD Negeri 105307sebelum diberi penyuluhan dan setelah diberi penyuluhan dengan menggunakan media flip chart dan boneka animasi.

Hal ini disebabkan boneka animasi menarik perhatian anak oleh karena bentuknya menyerupai boneka atau patung, sehingga tingkat pengetahuan anak lebih meningkat menjadi 95\%, yang sebelumnya pada penggunaan media flip chart hanya $55 \%$, berarti selisihnya adalah $40 \%$ setelah diberikan penyuluhan dengan media boneka animasi.

Saran

1. Perlunya menggunakan media yang tepat dan sesuai dengan sasaran pada saat melakukan penyuluhan agar pesan yang ingin disampaikan dapat lebih dipahami.

2. Dalam melakukan pendidikan kesehatan gigi, perlu melibatkan guru secara aktif agar selanjutnya guru mampu memberikan pendidikan kesehatan gigi dalam memotivasi anak secara mandiri.

3. Perlunya meningkatkan peran UKGS disekolah agar lebih memotivasi anak sekolah dalam kesehatan gigi.

4. Diharapkan kepada tenaga kesehatan untuk memberikan penyuluhan dan pelayanan kesehatan gigi secara berkesinambungan untuk mencapai derajat kesehatan gigi dan mulut yang optimal di SD Negeri 105307 Sukaraya Pancur Batu Tahun 2014./

\section{DAFTAR PUSTAKA}

Arikunto, S., 2006, Prosedur Penelitian, Rineka Cipta, Jakarta

Effendy, N., 1998, Dasar-dasar Keperawatan Kesehatan Masyarakat, EGC, Jakarta

Andhika, C., 2012. Kesehatan Gigi dan Mulut <http://Christinaandhika.health.kompas.com]

Hidayat, 2008. Metodologi Penelitian Kesehatan. <http://repository.usu.at.id/handle/123456789/27 931]

Gondoyoewono, 2004. Dasar-dasar Penyuluhan <http://Gondoyoewono.repository.usu.ac.id]

$<$ http://prpm.boneka.com]

Nofalia, Marina, 2010. Penyuluhan Kesehatan Gigi. <http://www.infogigi.com]

Notoatmodjo, S., 2005, Metodologi Penelitian Kesehatan, Rineka Cipta, Jakarta

Notoatmodjo, S., 2003, Ilmu Kesehatan Masyarakat, Rineka Cipta, Jakarta

Suiraoka, P., Supariasa, 2012, Media Pendidikan Kesehatan, Graha Ilmu, Yogyakarta. 